\title{
RUANG PENYEMBUHAN DENGAN SENI RUPA
}

\author{
Geraldina $^{1)}$, Alvin Hadiwono ${ }^{21}$ \\ 1) Program Studi S1 Arsitektur, Fakultas Teknik, Universitas Tarumanagara, \\ geraldinatriaz.315130232@stu.untar.ac.id
}

\begin{abstract}
Abstrak
Kehidupan di kota Jakarta merupakan kehidupan yang dipenuhi tekanan yang didapat dari pekerjaan, rendahnya tingkat pendapatan, kemacetan, dan kurangnya ruang terbuka hijau yang merupakan sarana penyejukan dan tempat berekreasi. Oleh karena itu, dalam lingkup metropolitan seperti Jakarta ini, dibutuhkan ruang-ruang baru yang dapat diakses public, baik secara jangkauan area, maupun secara jangkauan harga. Bertambahnya minat terhadap seni di Jakarta menjadi pertimbangan untuk membuat suatu destinasi wisata rohani yang menggunakan media seni sebagai cara penyembuhan. Efek ini dihasilkan dari kegiatan mengekspresikan diri melalui media seni ini menstimulasi otak untuk menyambungkan jaringan-jaringan di dalamnya agar saling berkomunikasi yang disebut "Brain Plasticity". Di dalam destinasi wisata ini, terdapat area-area yang dapat diakses public yang berupa ruang terbuka hijau dengan banyak penghijauan yang berada di luar bangunan. Tujuannya adalah agar semua lapisan masyarakat yang datang dapat menikmati ruang terbuka public yang terdapat di bangunan ini meskipun tidak masuk ke dalamnya dan membayar untuk menikmati wisata seni yang ada. Media seni yang digunakan sebagai destinasi wisata juga mengandung unsur penyembuhan bagi pengunjung yang datang. Penyembuhan ini pertama-tama menyembuhkan sisi spiritual pengunjung yang pada akhirnya sisi lain seperti mental dan fisik juga dapat tersembuhkan juga. Kegiatan yang dilakukan adalah dengan melihat-lihat karya seni dan mengerjakan kesenian itu sendiri. Seni rupa diambil menjadi kegiatan utama karena jenis seni itu tidak membutuhkan keahlian khusus, sehingga dapat lebih mudah untuk dilakukan semua orang dengan bantuan terapis yang disediakan.
\end{abstract}

Kata kunci: Seni Rupa, Brain Plasticity, Ruang Terbuka Hijau, Spiritual, Terapi Seni

\begin{abstract}
The life style in Jakarta City is the life that full of pressure from job, low GDP, traffic jam, and because of not enough public green space that people need to refreshing and recreation purpose. That's why in a metropolitan city scale like Jakrta, we need new spaces that public can access, as a price and as an easy find area. The increase of interest about art in Jakarta become the consideration to create a spiritual based tourism object that using art as a attraction. The effect makes the tissues on brain connected each other. This connection called "Brain Plasticity". In this tourism destination, there are plenty of green open space area that public can access. That areas located outside the main building, so public no need to enter and pay for it. The main goal to make a free public space is to create a space where all kinds of people from different layers can come here. It makes this place looks crowded, so it may attract people attention. The art platform that used also has a healing effect. The healing comes first from spiritual aspect and will be able to heal mental and physics also by the time. The activity about art that visitors do in this tourism destination is seeing artwork, experiencing some attractions, and doing art itself by their own hands with the help from therapist that we provide. We choose visual art to be our main attraction and activity, because it does not need any special ability and visual art is the common art that people use as a healing tools.
\end{abstract}

Keywords: Visual Art, Brain Plasticity, Green Open Space, Spiritual, Art Therapy 


\section{PENDAHULUAN}

\section{Latar Belakang}

Kehidupan di kota metropolitan seperti Jakarta ini membuat sering terjadinya tekanan secara psikologis atau stress. Beberapa factor seperti kemacetan, tekanan pekerjaan, kurangnya ruang terbuka hijau, merupakan penyebab-penyebab tingginya tingkat stress di kota Jakarta. Stress ini tidak dapat disepelekan, karena dapat menyebabkan berbagai jenis penyakit (psikosomatis). Penyakit psikomatis ini disebabkan oleh gangguan emosional yang menyebabkan tidak seimbangnya chakra (energy di dalam tubuh manusia), sehingga dapat menimbulkan berbagai penyakit fisik.

Kegiatan berwisata merupakan salah satu cara untuk mengurangi stress. Ada banyak manfaat berwisata yang berguna bagi penyembuhan jiwa. Kegiatan wisata ini dikategorikan sebagai "Wisata Religi" yang tidak hanya dapat menghilangkan stress, namun juga memiliki banyak manfaat lain, baik secara spiritual maupun sebagai penambah wawasan.

Destinasi wisata dengan unsur rohani di dalamnya di kota Jakarta ini masih kental dengan pemahaman yang mengarah kepada destinasi wisata yang berdasarkan agama-agama tertentu. Belum banyak diketahui bahwa unsur rohani tidak selalu mengarah kepada keagamaan saja, bila dilihat dari defisini-definisi kata "Spiritual" itu sendiri. Istilah rohani atau spiritual juga sebenarnya mengarah kepada kondisi mental dan kejiwaan manusia.

Dalam proyek tugas akhir ini, agar pemahaman istilah "rohani" menjadi lebih luas pada masyarakat Jakarta, maka desifini dari kata "rohani" yang dimaksudkan lebih diarahkan kepada istilah mental dan kejiwaan. Pengarahan ini bertujuan agar destinasi 517wisata rohani yang dibuat tidak hanya berlandaskan pada agama tertentu, tetapi dapat dinikmati secara lebih universal oleh segala kalangan yang ada di Jakarta.

Bertambahnya minat terhadap seni di Jakarta menjadi pertimbangan untuk membuat suatu destinasi wisata rohani yang menggunakan media seni sebagai cara penyembuhan. Telah banyak penelitian yang mengatakan bahwa seni memiliki efek therapeutic atau menyembuhkan, terutama dengan cara melakukan kegiatan membuat seni. Efek ini dihasilkan dari kegiatan mengekspresikan diri melalui media seni ini menstimulasi otak untuk menyambungkan jaringan-jaringan di dalamnya agar saling berkomunikasi yang disebut "Brain Plasticity".

Selain dengan cara mengerjakan kesenian, penyembuhan dengan media seni visual juga dapat dilakukan dengan menatapi lukisan-lukisan yang dapat membantu proses penyembuhan. Kumpulan koleksi-koleksi lukisan yang dapat membantu proses penyembuhan ini dapat dijadikan gallery yang memiliki sebuah alur perjalanan tertentu. Selain karena dapat dijadikan galeri, media penyembuhan menggunakan visual art dipilih karena sedang berkembangnya minat terhadap seni, terutama seni kontemporer di Jakarta.

\section{Susunan Penulisan}

Tujuan dibuatnya wisata rohani yang menggunakan seni kontemporer di Jakarta adalah agar masyarakat Jakarta menaruh perhatian lebih kepada industry seni di Jakarta yang saat ini mulai berkembang [9]. Dilihat dari segi rohani, wisata dengan media seni juga dapat menyembuhkan penyakit-penyakit mental dan fisik, serta melepaskan ketegangan [6]. Sedangkan manfaat dibuatnya wisata rohani dengan media seni bagi kota Jakarta adalah :

1. Sebagai stress reliever warga Jakarta

2. Sarana penyembuhan yang bersifat wisata bukan medis

3. Tempat untuk menyendiri dan kontemplasi

4. Meningkatkan minat terhadap seni kontemporer di Jakarta 


\section{KAJIAN LITERATUR}

Pada bagian Kajian Literatur, penulis perlu menuliskan kajian literatur (teori, buku, jurnal, dII) yang digunakan sebagai landasan analisis atau desain. Seluruh referensi yang digunakan harus tercantum dalam daftar referensi.

\section{Teori Architourism}

Ketika berbicara tentang pariwisata, bentuk dan struktur kota hanya merupakan beberapa dari antara komponen yang mempengaruhi interaksi di dalam atmosfir perkotaan dan menghasilkan pandangan-pandangan yang bermacam-macam dari turis. Goldner dan Ritchie (2009) juga mengeluarkan pemikiran tentang fenomena pariwisata, di mana mereka mengerti bahwa sebuah lingkungan yang terbangun sebuah dimensi dari komponen pariwisata yang diciptakan oleh manusia.

Tabel 1: Lingkungan Kota Yang Terbangun Sebagai Salah Satu Daya Tarik Pariwisata Di

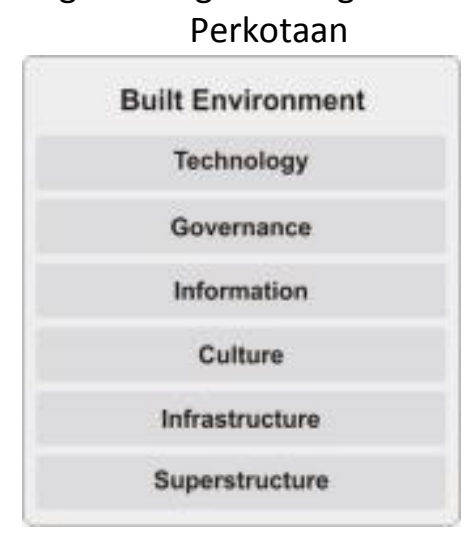

Sumber : Buku Architourism in Metropolis - Jan Specht

Finstein dan Judd (1999) memperkenalkan tiga klasifikasi sebuah kota yang akan dikinjungi turis yang juga berpegang pada perbedaan antar tujuan dari pembuatan destinasi wisata.

Tabel 2 : Tipe kondisi perkotaan yang dapat menjadi daya tarik turis

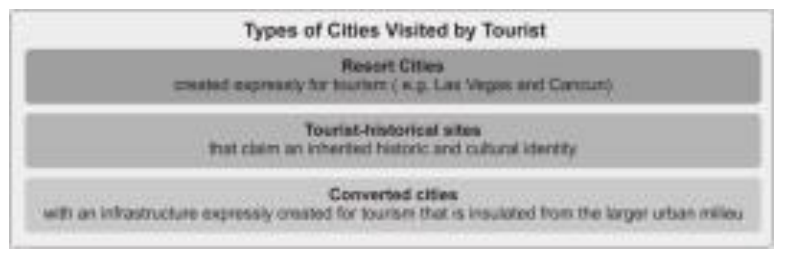

Sumber : Buku Architourism in Metropolis - Jan Specht

\section{Definisi Rohani}

Kata "rohani" adalah sesuatu yang berhubungan dengan jiwa dan roh manusia yang bersinggungan dengan alam yang lebih tinggi dari manusia yang tidak memiliki wujud fisik yang bersifat supranatural. Kata "rohani" memiliki arti yang berlawanan dengan kata "duniawi" yang terdiri dari sesuatu yang bersifat material dan berwujud fisik. Namun, kata "rohani" ini sebenarnya tidak selalu berhubungan dengan agama.

\section{Akibat Tekanan Emosional}

Stress dan masalah-masalah emosional lainnya yang tidak mendapat penanganan yang tepat atau bahkan dibiarkan juga menyebabkan masalah-masalah kesehatan fisik. Masalah ini disebut : Psikosomatis. 
Masalah ini kadang tidak dapat diketahui penyebabnya secara medis. Apabila dicek ke dokter, maka hasilnya kesehatan fisik akan baik-baik saja, namun tetap merasa sakit. Dalam kasus-kasus seperti ini menandakan bahwa terjadi ketidakseimbangan energy di dalam tubuh. Jenis penyembuhan sendiri ada banyak cara, salah satunya adalah dengan penyembuhan holstik, yaitu menyembuhkan lewat energy tubuh.

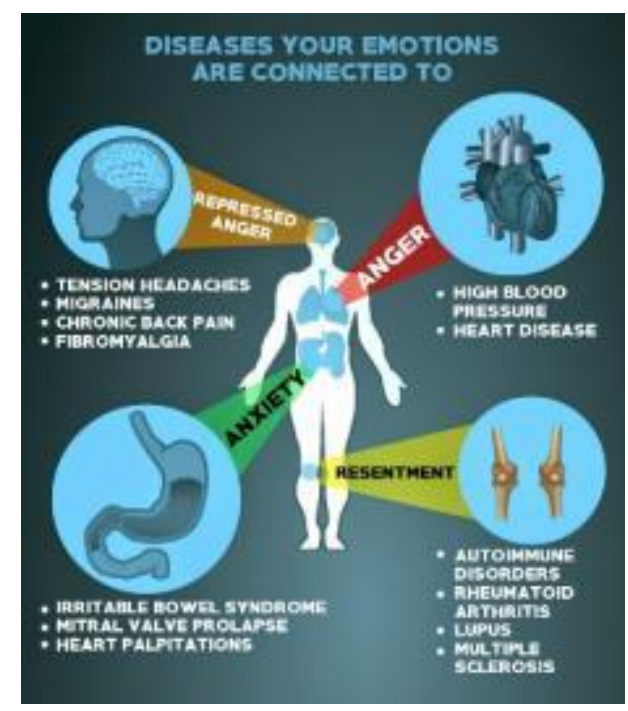

Gambar 1. Penyakit Psikosomatis

Sumber : www.verywellmind.com

\section{Pengertian Art Therapy}

Melalui kegiatan membuat karya seni, orang akan dapat mengembangkan kemapuan yang merangsang kemampuan kognitif, meningkatkan kepekaan terhadap diri sendiri dan orang lain, dan membantu mengatasi gejala keterbatasan yang diakibatkan cacat atau sakit. Tujuan utama dari art therapy adalah untuk membantu orang menyembuhkan luka mental dan emosional mereka semaksimal mungkin.

Seni menyembuhkan dengan cara menetralkan pikiran negative, sehingga kadar hormone kortisol pemicu stress menjadi berkurang dan system imun tubuh meningkat. Ketika system imun tubuh meningkat, maka pikiran positif akan lebih mudah untuk dimunculkan. Pikiran positif tersebut melepaskan hormon-hormon yang meningkatkan kebahagiaan, seperti hormone endorphin dan dopamine yang berfungsi meningkatkan system imun tubuh.
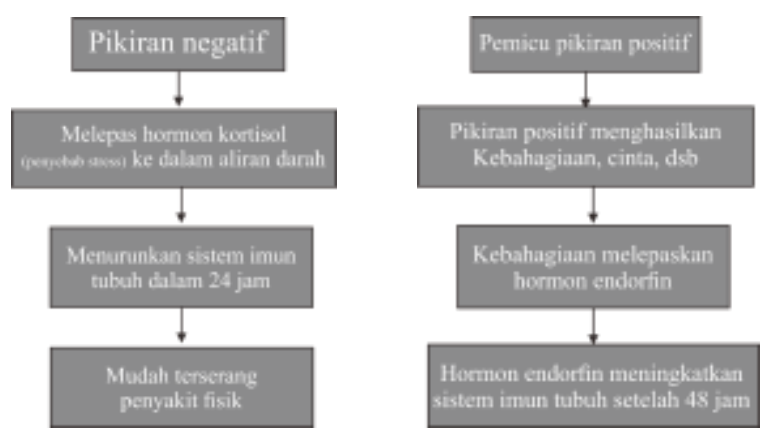

Gambar 2. Bagaimana art therapy menyembuhkan sisi spiritual, mental, dan fisik Sumber : Buku Art and Healing - Barbara Ganim

\section{Macam-macam Penyembuhan yang didapat dari Art Therapy}

1. Seni Dapat Menyembuhkan Gangguan Mental Ringan

2. Seni Dapat Melatih Kemampuan Kognitif 
3. Seni dapat membantu proses penyembuhan sakit fisik

4. Seni Dapat Menyembuhkan Masalah Emosional

\section{METODE}

Sedangkan metode komparasi dilakukan dengan cara membandingkan hasil temuan teoriteori dan studi-studi yang ada antara satu dengan yang lain. Perbandingan ini juga dilakukan dalam melihat contoh-contoh studi kasus yang telah terjadi, dengan tujuan agar mendapatkan benang merah dan klasifikasi-klasifikasi dari tema besar yang diambil, yaitu tema visual art.

\section{DISKUSI DAN HASIL}

Metode penyembuhan menggunakan seni yang paling umum ditemukan adalah metode visual arts, baik secara aktif (dengan membuat karya seni) ataupun seara pasif (hanya dengan menatap dan menginterpretasikan karya seni yang bersifat menyembuhkan). Metode ini dipilih karena visual art sedang banyak diminati di Jakarta. [5] Berbagai macam jenis visual art yang mengandung unsur penyembuhan adalah

\section{Mirror Maze Room}

Dalam buku Healing Space yang ditulis oleh Dr. Esther Sternberg, seorang mantan wakil direktur perusahaan theme park Disney Land yang melakukan riset tentang bagaimana sebuah tempat dapat mempengaruhi kondisi psikologis pengunjungnya, dikatakan bahwa ada jenisjenis ruang yang dapat menyembuhkan dan ada jenis-jenis ruang yang justru sebaliknya dapat membuat tekanan, memicu adernalin, dan membuat stress dan frustasi. Ruangan tersebut contohnya : Labirin, maze, dan ruangan-ruangan yang gelap. Dalam proyek tugas akhir ini, mirror maze room digunakan untuk menaikkan adernalin pengunjung, memicu rasa takut, dan membuat panik. Ketika tekanan mental dialami pengunjung, maka emosi-emosi terpendam yang ada di alam bawah sadar pengunjung akan muncul, misalnya trauma dan rasa takut. Saat pengunjung telah menyadari emosi-emosi negatif yang dirasakannya, maka efek penyembuhan dari seni tersebut akan lebih terasa.

\section{Infinity Room}

Instalasi seni yang diciptakan oleh seniman Jepang, Yayoi Kusama. Tujuan Yayoi membuat infinity room ini adalah, ia ingin siapa pun yang berdiri di tengah ruangan dengan refleksi yang dilipatgandakan tanpa batas itu untuk terkoneksi secara psikoseksual dengan dirinya sendiri, terutama tubuh yang dilihatnya di cermin. Instalasi ini diciptakan berdasarkan pengalaman pribadi Yayoi kusama yang sering mengalami halusinasi semasa kecilnya. Karena itu, dalam proyek tugas akhir ini, infinity room ini digunakan sebagai media penyembuhan gangguan mental, namun dengan cara memicu halusinasi terlebih dahulu, agar semua masalah-masalah psikologis yang dialami pengunjung dapat muncul ke alam sadar. Instalasi seni ini menggunakan perpaduan kaca-kaca pada tembok, dinding, dan langit-langit ruangan yang saling berhadapan, dipadukan dengan bola-bola lampu. Setting seperti ini akan menghasilkan ilusi optik yang memberi efek suatu ruang yang tidak berujung, karena pertemuan kaca-kaca tersebut dan perpaduan bola lampunya.

3. Fiber Art Installation dan Instalasi instalasi lain yang interaktif

Instalasi yang interaktif mengharuskan pengunjung untuk bergerak melewatinya. Proses bergerak ini berguna untuk melatih fungsi kognitif. Latihan kognitif ini terutama diperlukan oleh orang-orang dengan Trauma Brain Injury atau cidera otak. Selain orang-orang dengan cidera otak, kaum lansia juga membutuhkan latihan kognitif agar terhindar dari kemungkinan terkena penyakit dementia atau penyakit kognitif lainnya. Penggunaan karya instalasi seni sebagai media penyembuhan cidera otak dilakukan oleh Tracie McCambridge yang jgua adalah seorang pasien cidera otak. la menyampaikan idenya tersebut kepada neuro-logist nya di Wexner Medical Centar dan melakukannya idenya itu dan berhasil membuat cidera otak yang dideritanya berkurang. 


\section{Sculpture Garden}

Penemuan yang dilakukan oleh peneliti-eneliti dari California University in Berkeley mengatakan bahwa perpaduan antara seni dan alam dapat meningkatkan system kekebalan tubuh. Hal ini disebabkan karena adanya penurunan kadar cytokine, unsur kimiawi di dalam tubuh yang menyebabkan pembengkakan, memicu diabetes, penyakit jantung, dan penyakit lainnnya. Melihat sesuatu yang hijau bagi penderita sakit fisik juga memiliki manfaat yang dirasakan pertama-tama dari penyembuhan mental lewat pemandangan pohon-pohon hijau yang dinikmati. Kesembuhan mental ini berupa rasa tenang yang mengurangi tingkat kecemasan. Dari kesembuhan mental ini, penyakit fisik yang diderita juga akan berkurang, karena meningkatnya kelancaran aliran darah yang berasal dari reaksi-reaksi listrik dan kimia yang dilepaskan tubuh melalui sensory cortex pada otak yang mengenali warna hijau sebagai warna yang menenangkan. Berada di bawah matahari juga memberikan efek penyembuhan yang berasal dari warna-warna yang dihasilkan oleh spectrum matahari tersebut.

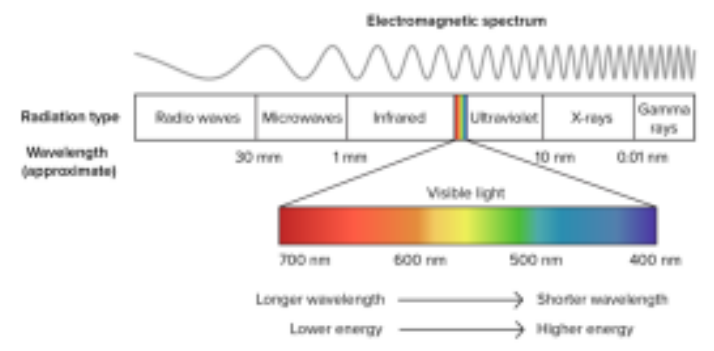

Gambar 3. Kesembuhan yang dihasilkan warna dari sinar marahari Sumber: www.ncbi.nlm.nih.gov

\section{Efek Air Sebagai Pendukung Healing}

Orfeu Buxton, peneliti dari Live Science, menuturkan bahwa suara gemericik air bisa memengaruhi pikiran seseorang agar tetap tenang, nyaman, dan tidak khawatir dengan keadaan.

\section{Analisis Makro}

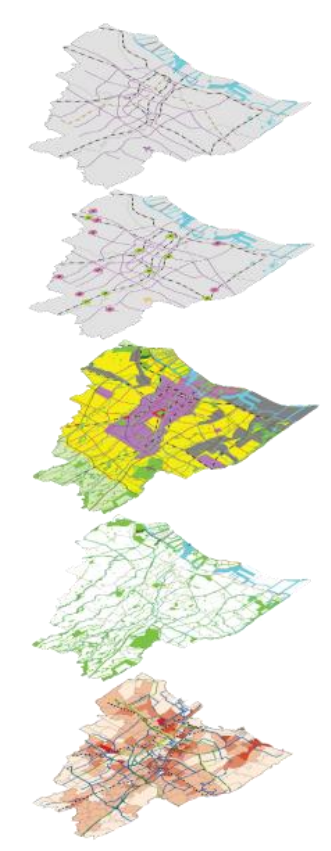

Gambar 4. Analisis Makro

Sumber: Data dari LRK dan RTRW DKI Jakarta, diolah oleh penulis, 2018 
Rencana penambahan lokasi-lokasi jalan arteri: menambah akses transportasi umum bagi turis. Jalan Arteri pada RTRW 2030 terlihat mengalami penambahan, yaitu dari arah Tangerang dan Bekasi. Rencana penambahan fasilitas Park and Ride: memungkinkan turis untuk meninggalkan mobilnya dan menyambung menggunakan transportasi umum. Rencana pemusatan kegiatan perekonomian, perdagangan, dan jasa ke bagian tengah kota: Jalan-jalan besar akan menjadi jalur yang banyak dilalui orang. Rencana pengembangan RTH ke arah selatan: udara yang lebih sejuk secara makro untuk melakukan kegiatan kontemplatif dan healing. Rencana penambahan transportasi umum : Dengan adanya LRT dan MRT yang datang dari kota satelit seperti Bekasi dan Tangerang, maka potensi wisatawan di kota Jakarta dapat bertambah. Berdasarkan lokasi-lokasi galeri seni, museum seni, dan komunitas seni yang ada di Jakarta, lokasi yang paling banyak terdapat museum adalah di kawasan Jakarta Pusat dan di kawasan Jakarta Selatan.

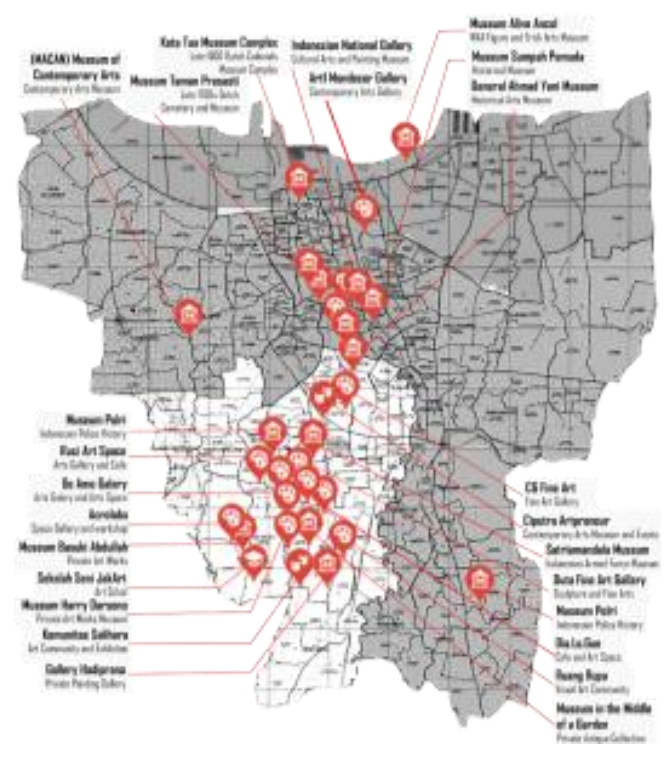

Gambar 5. Peta Persebaran Art Space di Jakarta

Sumber: Data dari Google Maps, diolah oleh penulis, 2018

Museum-museum yang ada di kawasan Jakarta Pusat lebih bersifat historical dan edukatif dibandingkan museum-museum dan galeri-galeri lukisan yang ada di Jakarta Selatan, yang lebih bersifat koleksi pribadi dan kontemporer. Dengan banyaknya galeri dan museum lukisan di Jakarta Selatan, maka dapat dikatakan bahwa kawasan ini memiliki minat seni yang cukup tinggi.

\section{Analisis Messo}

Jakarta Selatan merupakan daerah penghijauan paling utama di Kota Jakarta, sehingga udara secara makro lebih sejuk daripada di kotamadya lain. Transportasi umum banyak dilalui pada Kecamatan Tebet, Kecamatan Kebayoran Lama, Kecamatan Pancoran, dan Kecamatan Setiabudi yang terdapat jalan-jalan arteri dan dilewati jalur. Di kawasan Jakarta selatan, banyak didapati tempat-tempat pemulihan spiritual seperti meditasi dan yoga di. Minat masyarakat sekitar untuk mencari ketenangan batin cukup tinggi. 


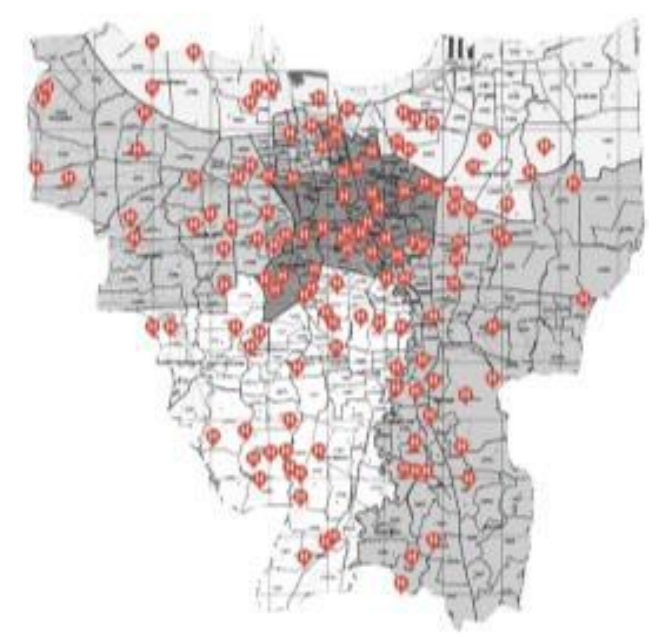

Gambar 6. Peta Persebaran Rumah Sakit di Jakarta Sumber: Data dari Google Maps, diolah oleh penulis, 2018

Bila dilihat dari jumlah rumah sakit di Jakarta Selatan, posisi tapak akan mengarah ke Kecamatan Setia Budi, Kebayoran Lama, atau Kecamatan Cilandak.

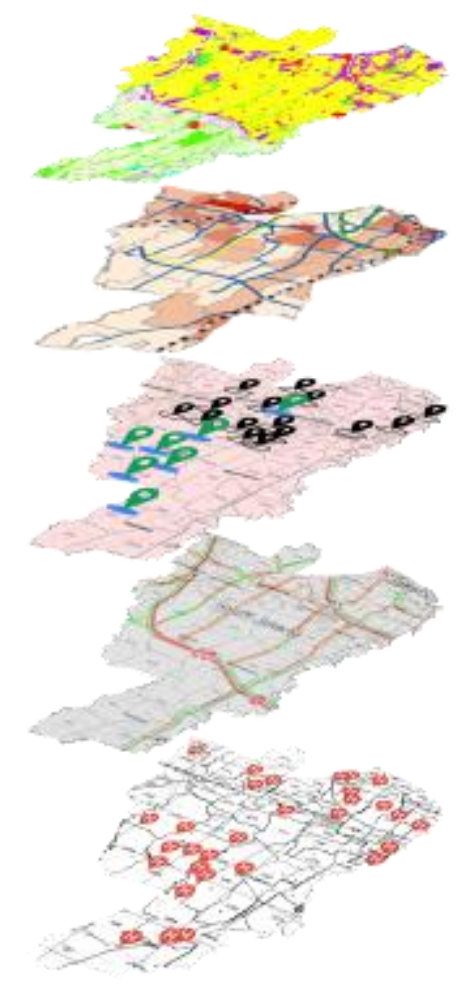

Gambar 7. Analisis Messo

Sumber: Data dari LRK dan RTRW DKI Jakarta, diolah oleh penulis, 2018

Kesimpulan yang dihasilkan dari analisis messo antar kecamatan : Kecamatan yang memiliki point tertinggi dalam analisis tapak secara messo adalah Kecamatan Kebayoran Lama dengan 9 kriteria yang terpenuhi dari 12 kriteria tapak yang ideal bagi program. Kriteria-kriteria tersebut antara lain:

1. Banyaknya jumlah art space di Kebayoran Lama

2. Mudahnya transportasi umum

3. Akses kendaraan yang mudah karena hierarki jalan di Kecamatan ini tinggi, karena banyak terdapat jalan-jalan arteri. 
4. Memiliki RTH yang banyak (urutan ke-3 terbanyak di Jakarta Selatan)

5. Memiliki jumlah Rumah Sakit terbanyak (urutan ke-2 terbanyak di Jakarta Selatan)

6. Jumlah penduduk terbanyak di Jakarta Selatan

7. Banyak terdapat tempat meditasi dan penyembuhan spiritual

8. Tingkat banjir rendah

9. Berdasarkan harga jual tanah, memiliki tingkat ekonomi menengah ke atas

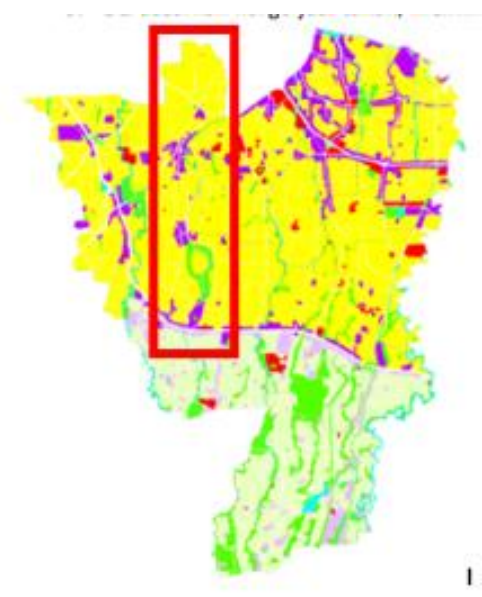

Gambar 8. Posisi Kecamatan Kebayoran Lama pada Zonasi Kotamadya Jakarta Selatan Sumber: Data dari RTRW DKI Jakarta

Dilihat dari zonasi, kawasan Kebayoran Lama memiliki jumlah penduduk kedua terbanyak di Jakarta Selatan dan ke-11 terbanyak di seluruh wilayah Jakarta. Salah satu faktornya adalah karena banyak zonasi perumahan di Kecamatan Kebayoran Lama. Banyaknya zonasi perumahan menjadi tanda yang baik bagi wisata, karena kawasan tersebut adalah rumah bagi banyak orang. Jika orang berada di rumah, berarti ia sedang tidak bekerja. Kegiatan wisata umumnya dilakukan ketika orang sedang memiliki waktu luang, seperti akhir pekan atau tanggal merah. Salah satu faktornya adalah karena banyak zonasi perumahan di Kecamatan Kebayoran Lama. Banyaknya zonasi perumahan menjadi tanda yang baik bagi wisata, karena kawasan tersebut adalah rumah bagi banyak orang. Jika orang berada di rumah, berarti ia sedang tidak bekerja. Kegiatan wisata umumnya dilakukan ketika orang sedang memiliki waktu luang, seperti akhir pekan atau tanggal merah.

\section{Analisis Mikro}

Lokasi : Kelurahan Pondok Pinang, Kecamatan Kebayoran Lama, Kota Jakarta Selatan

Batasan tapak :

- JI. TB. Simatupang dan Flyover tol Jakarta Outer Ring Road (barat)

- JI. Metro Pondok Indah dan Koridor 8 Bus Transjakarta Harmoni - Lebak Bulus (selatan)

- Perkantoran Wisma BCA (timur)

- Perumahan Elite Pondok Indah (utara)

Zona : 08.024.K.1.a.b zona perkantoran, perdagangan, dan jasa

Luas tapak : 5.000 meter $^{2}$

KDB : $50 \%\left(2.500 \mathrm{~m}^{2}\right)$

$\mathrm{KLB}: 2.00\left(10.000 \mathrm{~m}^{2}\right)$

KTB: $50 \%\left(2.500 \mathrm{~m}^{2}\right)$

KB: 4

$\mathrm{KDH}: 35 \%\left(1.750 \mathrm{~m}^{2}\right)$

Transportasi umum di kawasan ini tergolong sangat mudah dan akan semakin mudah dalam beberapa tahun ke depan. Stasiun MRT terdekat (Stasiun Lebak Bulus) yang direncanakan 
berada 300 meter dari tapak, sedangkan halte busway terdekat (halte busway Pondok Indah 1) berada 50 meter dari tapak. Keberadaan transportasi umum ini memudahkan warga Jakarta untuk mengunjungi tapak. Persebaran rumah sakit pada radius $700 \mathrm{~m}$ dari tapak dan posisi jalan arteri yang menghubungkan kawasan Kebayoran Lama-Lebak Bulus dan kawasan Tangerang-Bekasi, melewati kawasan Cilandak-Fatmawati-PasarMinggu yang merupakan kawasan komunitas seni, galeri-galeri, museum-museum seni kontemorer. Pesebaran rumah sakit ini diperlukan untuk mengetahui seberapa dekat lokasi tapak dengan orang-orang yang membutuhkan kesembuhan secara fisik. Orang yang baru sembuh dari pasca operasi dan mengalami sakit menahun dapat diringankan, bahkan disembuhkan dakitnya melalui media seni, seperti pembahasan pada bab sebelumnya.

Keberadaan hotel-hotel bintang 3-5 ini diperhatikan untuk melihat apakah lokasi tapak memenuhi "Konsep Kriteria Pariwisata Indonesia" yang merupakan program dari dinas pariwisata Indonesia, yaitu 3A yang salah satunya adalah unsur Amenities. Unsur ini terdapat pada radius $700 \mathrm{~m}$ dari tapak, sehingga program pada tapak dibutuhkan untuk menunjang fungsi-fungsi hotel-hotel yang ada di sekitar tapak.

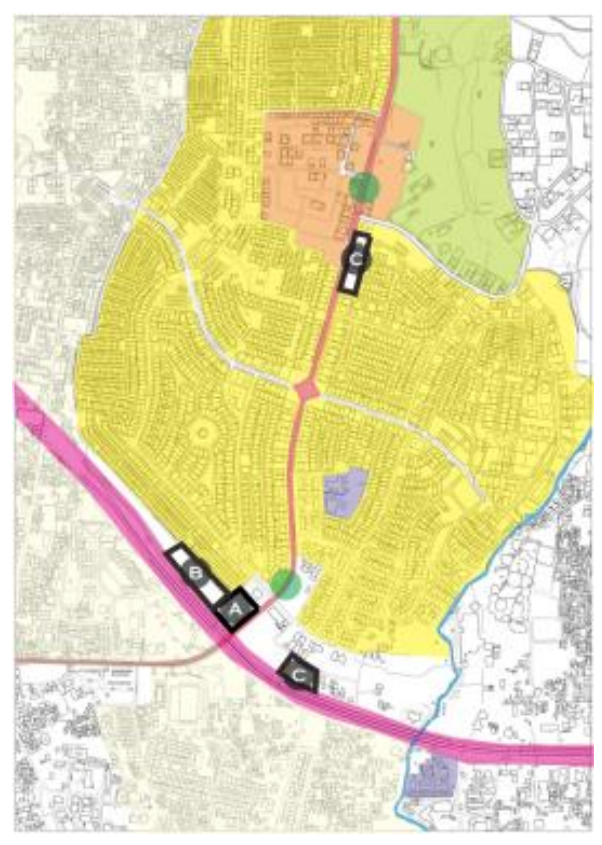

Gambar 9. Investigasi Kawasan

Sumber: Data dari LRK DKI Jakarta, Google Maps, dan databoks.co.id yang diolah penulis, 2018

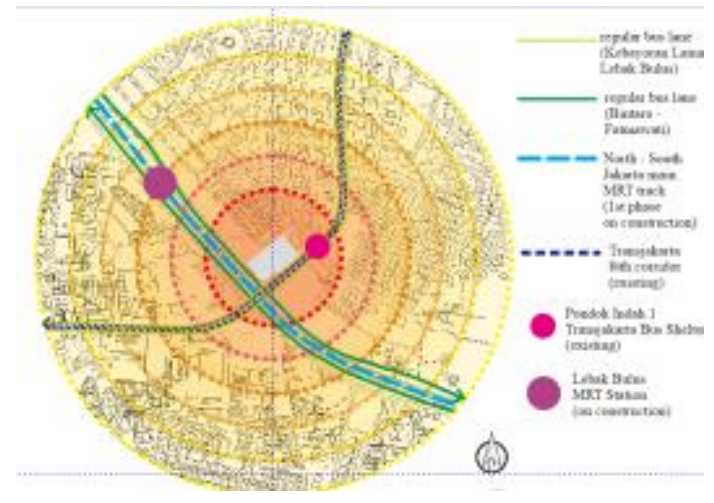

Gambar 10. Analisis Transportasi Umum

Sumber: Data dari LRK DKI Jakart dan, Google Maps yang diolah penulis, 2018 


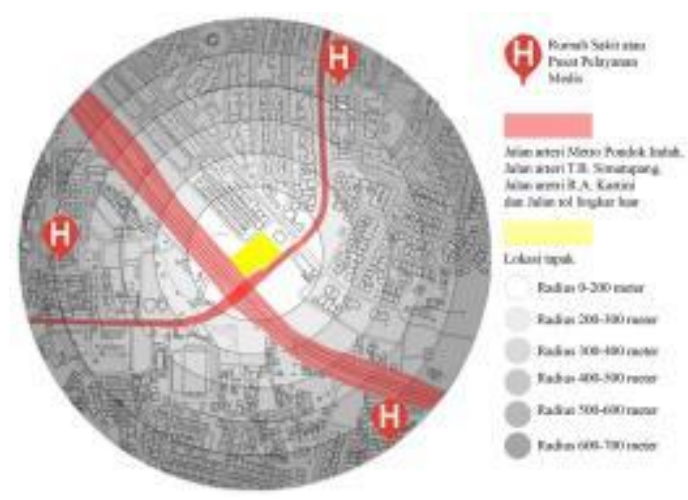

Gambar 11. Analisis Persebaran Rumah Sakit di radius 200-700 meter dari tapak terpilih Sumber: Data dari Google Maps, yang diolah penulis, 2018

\section{Proses Gubahan Massa}

Gubahan Massa terbentuk dari analisis tapak. Bentuk yang meruncing merupakan usaha untuk membuat shadding di dalam bangunan agar matahari tidak secara langsung masuk ke dalam bangunan. Shadding ini penting karena bila kenyamanan thermal tidak tercapai dengan baik, maka bangunan tidak dapat memberikan fungsi penyembuhan yang maksimal, karena pengunjung akan terganggu fokusnya oleh kenyamanan thermal yang buruk. Bentuk yang meruncing ini memiliki kesan yang menusuk, sehingga kurang sesuai untuk bentuk bangunan yang bertujuan menyembuhkan. Namun pengalaman ruang akan penyembuhan tidak dirasakan dari bentuk eksterior, tetapi dari bentuk interior. Karena itu, material dan pembentuk suasana menjadi hal yang penting bagi bangunan ini. Selain itu, bentuk yang tajamtajam pada penerapannya dibuat menjadi lebih tidak tajam dengan permainan siku dan ketinggian bangunan.

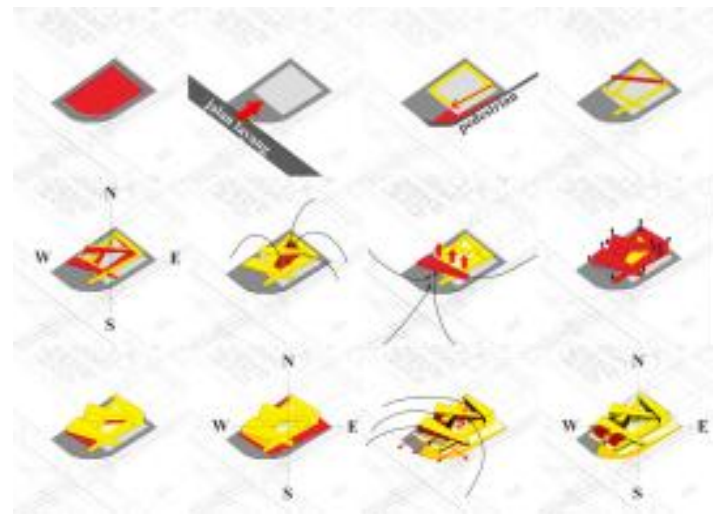

Gambar 12. Design Scheme dari analisis mikro tapak yang membentuk gubahan massa Sumber: Penulis, 2018

\section{Konsep Perancangan}

Seperti pada pembahasan sebelumnya, bahwa ada beberapa jenis media seni yang digunakan sebagai destinasi wisata dan sebagai sarana penyembuhan juga. Alur yang tercipta akan menjadi seperti ini: 


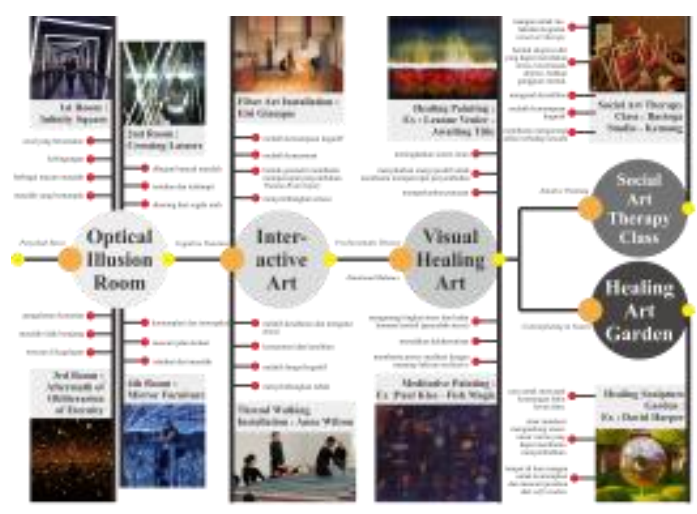

Gambar 13. Diagram Alur Perjalanan Wisata Sumber: Penulis, 2018

Dalam alur tersebut, pengunjung akan merasakan naik turun emosi yang akan membantu penyembuhan jiwa.

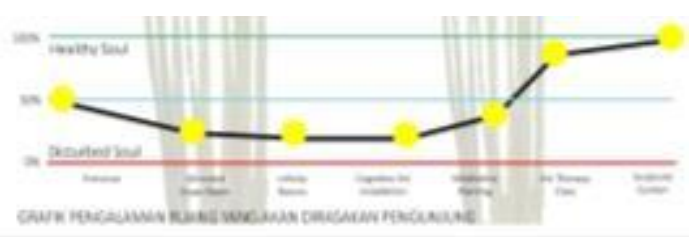

Gambar 14. Grafik pengalaman ruang yang akan dirasakan pengunjung secara spiritual Sumber: Penulis, 2018

Konsep berupa alur, namun pengunjung dibebaskan untuk memilih alurnya sendiri tanpa harus terpaksa mengikuti perjalanan yang telah ditentukan.

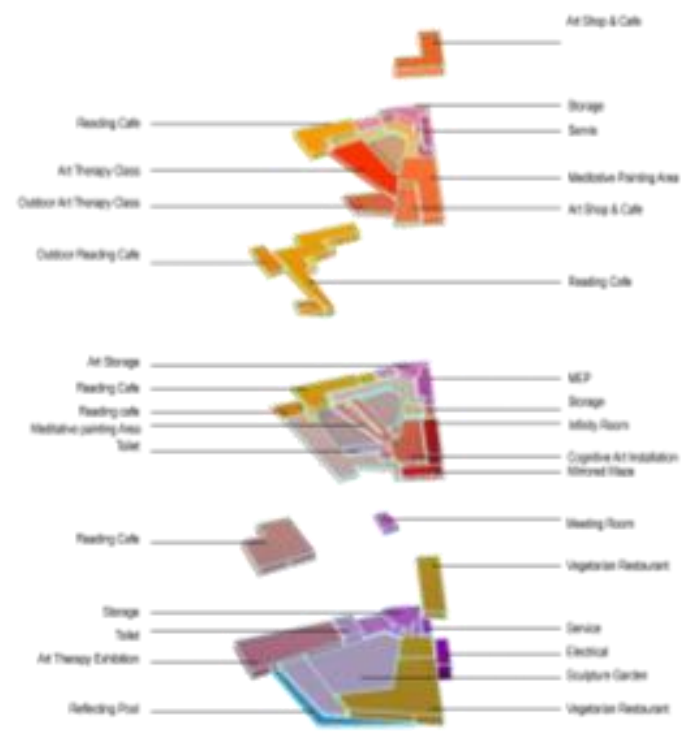

Gambar 15. Zona Program Ruang

Sumber: Penulis, 2018 


\section{Program Ruang}

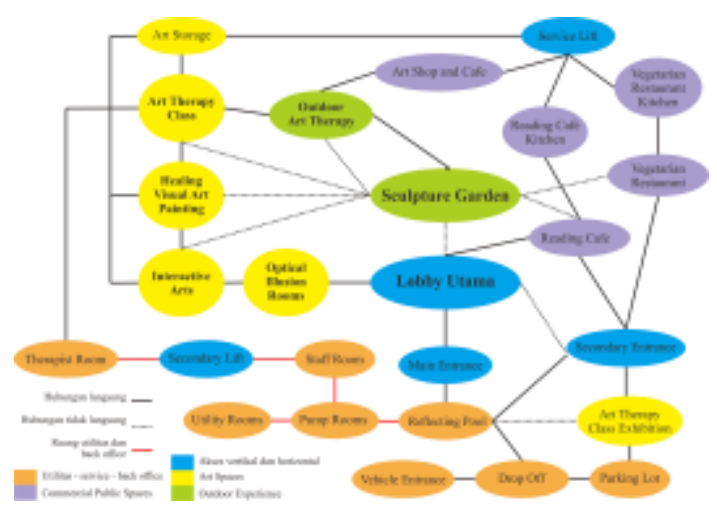

Gambar 16. Bubble Hubungan Antar Ruang Sumber: Penulis, 2018

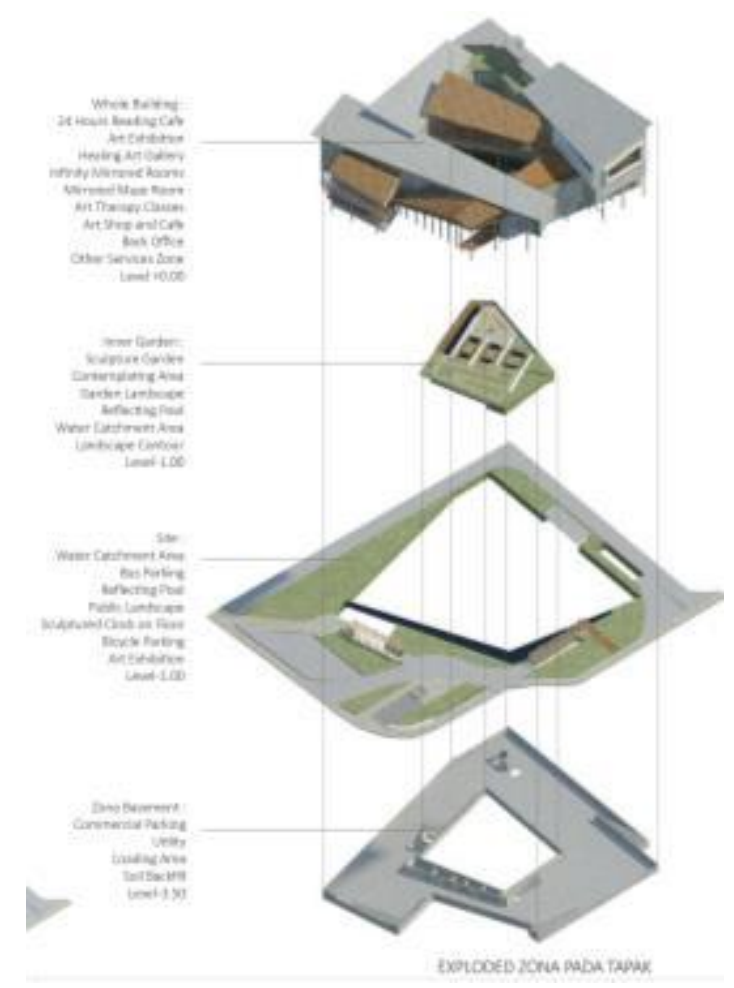

Gambar 17. Zona Pada Denah

Sumber: Penulis, 2018

Ruangan-ruangan yang ada dan penjelasannya adalah sebagai berikut :

1. Main entrance with reflecting pool

2. Lobby Utama

3. Visual Art Healing Space - Mirrored Maze Room

4. Visual Art Healing Space - Optical Illusion Rooms

5. Visual Art Healing Space - Interactive Art

6. Visual Art Healing Space - Meditative Painting

7. Visual Art Healing Space - Social Art Therapy Class

8. Visual Art Healing Space - Sculpture Inner Garden

9. Reading Café 
10. Art Therapy Exhibition

11. Outdoor Public Plaza

12. Basement parking

13. Toilet

14. Utility rooms

15. Therapist Room

16. Management Office

\section{Konstruksi yang Dipakai Pada Bangunan}

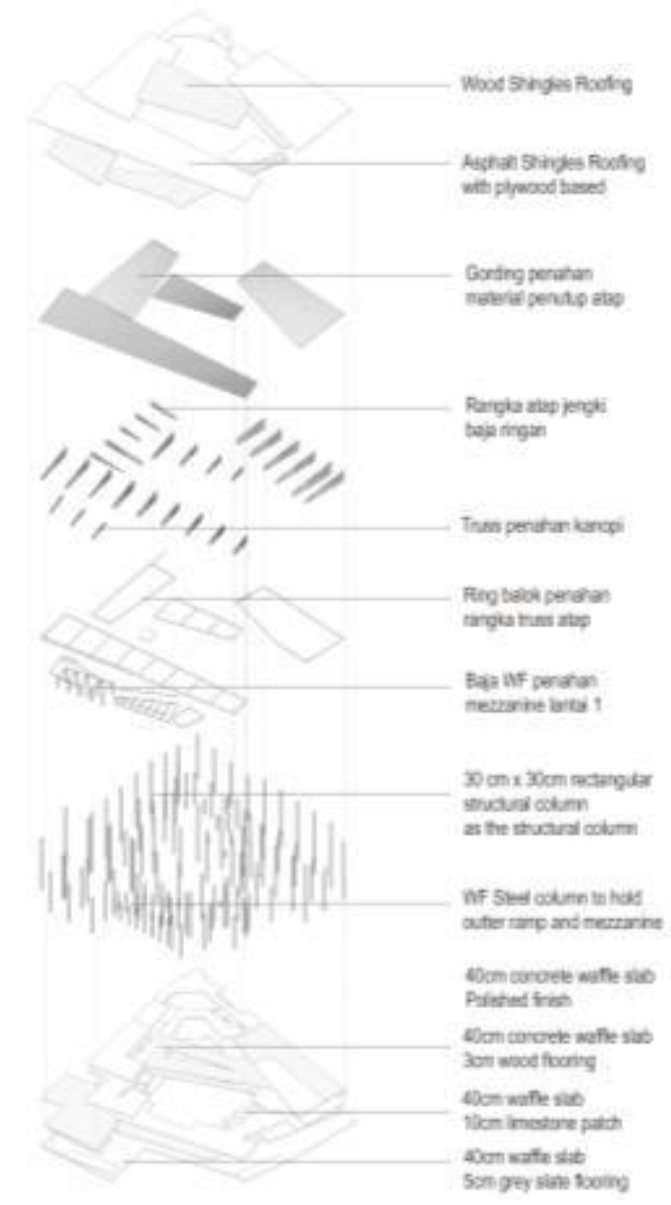

Gambar 18. Aksonometri Bangunan

Sumber: Penulis, 2018

Konstruksi bangunan menggunakan waffle slab dengan pertimbangan :

- Mengurangi ketinggian dari lantai ke lantai, sehingga plafon bisa lebih tinggi karena pada system waffle slab, plat lantainya sendiri sudah merupakan balok yang sangat padat.

- Karena susunan balok-balok kecil yang sangat padat pada plat lantai (ketebalan $40 \mathrm{~cm}$ ) dengan jarak antar balok per $60 \mathrm{~cm}$, maka struktur bangunan juga menjadi lebih kuat daripada struktur konvensional, sehingga jarak antar kolom dapat mencapai 15 meter dengan ukuran kolom hanya $30 \mathrm{~cm}$. Secara sirkulasi lebih menguntungkan.

Konstruksi rangka atap menggunakan baja ringan dengan pertimbangan :

- Sistem truss lebih mudah dibentuk, sehingga untuk bentuk atap yang tidak modular, sistem truss memudahkan pengerjaan.

- Rangka atap baja ringan memiliki bobot yang lebih ringan daripada sistem lain, sehingga dapat mengurangi beban bangunan.

- Srcara harga lebih terjangkau, karena tidak memerlukan reng. 
Konstruksi kolom menggunakan kolom beton dengan metode cor di pabrik (precast) ukuran $30 \times 30 \mathrm{~cm}$ dengan pertimbangan :

- Mudah dalam pemasangan di tempat dan tidak membuat kotoran yang terlalu banyak.

- Ukuran kolom modular, sehingga secara harga lebih hemat.

- Pengerjaan lebih cepat

\section{Sistem Utilitas Bangunan}

Utilitas air bersih menggunakan booster pump, reservoir atas, dan terdapat ground water tank di dekat booster pump yang airnya berasal dari sumur deep well, air hasil filtrasi WTP yang dialirkan ke ruang pompa reflecting pool, dan air PAM. Utilitas air kotor menggunakan biotank yang terdapat pada ruang pompa pengolahan air kotor (STP) yang berfungsi menyaring air kotor sebelum dibuang ke roil kota dan terdapat system filtrasi berupa Water Treatment Plant (WTP) di sebelahnya untuk dialirkan kembali ke bangunan.

Utilitas sprinkler berasal dari air filtrasi WTP yang dialirkan ke pompa seperti booster pump yang khusus mengalirkan air ke sprinkler. Air sprinkler akan otomatis menyala ketika smoke detector mendeteksi asap. Utilitas listrik menggukanan listrik dari PLN yang diterima travo, kemudian dialirkan ke seluruh bangunan. Terdapat mesin genset di sebelah ruang travo agar aliran listrik dapat segera dialihkan ke generator apabila terjadi pemadaman listrik dari PLN.

\section{KESIMPULAN DAN SARAN}

\section{Seni Sebagai Wisata di Kota Metrolipos}

Meningkatnya minat seni di Jakarta menjadi alasan mengapa seni dipilih sebagai destinasi wisata di kota Jakarta. Contoh yang menjadi parameter adalah jumlah pengunjung di Museum MACAN Jakarta Barat yang semakin meningkat dalam periode satu tahun. Selain karena minat seni yang sedang meningkat di Jakarta, seni juga mengandung unsur penyembuhan, terutama jika seseorang melakukan kegiatan seni dengan arahan-arahan dari terapis. Unsur penyembuhan ini dimulai dari sisi spiritual (jiwa) seseorang yang lama kelamaan dapat menyembuhkan sisi lain, seprti mental dan fisik seseorang.

\section{Jenis Seni yang Digunakan untuk Mencapai Penyembuhan}

Berdasarkan teori-teori yang telah dikaji tentang minat dan jenis seni yang paling mudah untuk diterapkan sebagai destinasi wisata, maka dibuatlah seni rupa (visual art) sebagai bentuk seni yang dipakai untuk membuat tempat wisata yang bersifat menyembuhkan. Seni rupa dipakai sebagai tema utama karena membuat seni rupa tidak membutuhkan keahlian khusus, sehingga setiap orang dapat mengerjakannya.

\section{Penentuan Lokasi Wisata Penyembuhan dengan Seni Rupa}

Penentuan lokasi dilakukan terutama berdasarkan factor transportasi umum yang mudah dijangkau dan diakses public, seperti nus transjakarta, MRT, atau LRT. Jenis jalan juga menjadi pertimbangan dalam memilih tapak. Jalan yang merupakan jalan arteri pasti akan lebih banyak dilalui orang dan lebih beragam arah datangnya. Apabila destinasi wisata berada di jalan yang ramai, maka akan lebih mudah dijumpai dan dikenali orang. Destinasi wisata juga lebih memungkinkan untuk menjadi level internasional.

Untuk itu, dipilihlah tapak di kawasan Pondok Indah, Kelurahan Pondok Pinang, Kecamatan Kebayoran Lama, kota Jakarta Selatan. Tapak ini berada langsung di jalan arteri sekunder Jl. Metro Pondok Indah di sisi timur yang merupakan jalur utama yang menghubungkan kota Depok dan Jakarta Selatan, yang menyambung ke Jl. Panjang yang terhubung ke Jakarta Barat. Di sepanjang jalan ini juga terdapat jalur bus transjakarta koridor 8 . Sedangkan di sisi selatan tapak, terdapat jalan arteri primer T.B. Simatupang dan J. R.A. Kartini di seberangnya. Jalan ini sangat special karena merupakan jalan utama yang menghubungkan Kota Tangerang dan Kota Bekasi. Selain itu, di sepanjang jalur ini terdapat Jalan Tol Jakarta Outter Ring Road, atau Tol 
Lingkar Luar yang menghubungkan seluruh kota Jakarta dan sekitarnya melalui jalur pinggir kota.

\section{Ruangan yang Tercipta dan Manfaatnya}

Setelah memilih jenis seni dan lokasi tapak, maka yang paling utama adalah menentukan program yang ada di dalam bangunannya. Ruangan-ruangan yang dibuat bertujuan untuk menjadi destinasi wisata yang dapat menyembuhkan sisi spiritual pengunjung. Karena destiniasi wisata harus membuat orang penasaran, maka beberapa ruangan dibuat sedikit menegangkan dan menghsruskan pengunjung mencari jalan keluar. Sementara ruanganruangan lain adalah galeri dan kelas seni yang dimana pengunjung merasakan ketenangan batin lewat seni yang dilihat dan lewat pengalaman mengerjakan seni tersebut.

\section{UCAPAN TERIMA KASIH}

Puji dan syukur kepada Tuhan Yang Maha Esa atas segala rahmat dan berkat yang telah diberikan-Nya, sehingga penulis dapat menyelesaikan tulisan ilmiah berjudul RUANG PENYEMBUHAN DENGAN SENI RUPA. Sebagai penutup penulis menyadari bahwa laporan ini masih banyak kekurangannya, namum penulis berharap semoga bermanfaat bagi pembaca yang memerlukannya.

\section{REFERENSI}

Sarno, John. (2006). The Divided Mind : The Epidemic of Mindbody Disorders. p.11.

McGuinness, M. M., \& Schnur, K. J. (2013). Art therapy, creative apperception, and rehabilitation from Traumatic Brain Injury. (p. 252-265). New York, USA : Guilford Press.

"UNWTO technical manual : Collection of Tourism Expenditure Statistics". World Tourism Organization, hal 10. 1995.

Specht, Jan. (2014). Architectural Tourism : Building for Urban Travel Destinations. Springler Gabler. Munich, Jerman.

Squires, G. Ed. (2002). Urban Sprawl: Causes, Consequences, \& Policy Responses. United States. The Urban Institute Press.

Eliade, Mircea. (2012). Sakral dan Profan. Yogyakarta : Fajar Pustaka Buku

Edwards, David. (2004). Art therapy. London: SAGE.

Ganim, Barbara. (1999). Art and Healing : Using Expressive Art to Heal Your Body, Mind, and Spirit. California, Amerika Serikat : Echo Point Book \& Media.

Sternberg, M. Esther. (2009). "Healing Spaces : the Science of Place and Well-being". Hal. 95. Massachussets, Amerika Serikat. Harvard University Press.

Breiling, Bryan. (1996). Light Years Ahead : The Illustrated Guide to Full Spectrum and Colored Light in Mindbody Healing. California, USA. Celestial Arts.

Nickl, Christine. Nickl, Hans. (2013). Healing Architecture. Berlin, Jerman : Braun Publishing.

Astutik, Yuni. (2018). Dalam artikel "Tak Selalu Gemerlap Dunia, Jakarta Juga Tawarkan Enam Wisata Religi". https://travelingyuk.com/wisata-religi-di-jakarta/86691/.

(diakses tanggal : 6 Agustus 2018)

Dinisari, Mia Citra. 9 Agustus 2018. Dalam artikel “Art Jakarta 2018 Dikunjungi Lebih dari 32.000 Pecinta Seni". http://lifestyle.bisnis.com/read/20180809/230/826205/art-jakarta2018-dikunjungi-lebih-dari-32.000-pecinta-seni

(diakses tanggal : 6 Agustus 2018)

Atwater, Brent. Dalam artikel "Now, It's Time for Paintings That Heal". http://www.susunweed.com/herbal_ezine/May05/empower.htm (diakses tanggal : 6 Agustus 2018)

Editor. 18 Juni 2015. Dalam artikel : "Bangkitnya Museum di Jakarta". Kutipan dari majalah DestinAsian Indonesia edisi Mei/Juni 2015. Dalam artikel : "Ruang Berliku". http://destinasian.co.id/bangkitnya-museum-di-jakarta/4/ 
(diakses tanggal : 10 Agustus 2018)

Moore, Rowan. 2017. The Bilbao Effect : How Frank Gehry's Guggenheim Started a Global Craze. https://www.theguardian.com.

(diakses tanggal : 3 Juli 2018)

Scott, Elisabeth. 12 Juni 2018. Dalam artikel : "Prevent Stress-Related Psychosomatic Illness." 